\title{
Physiological targets of salicylic acid on Artemisia aucheri BOISS as a medicinal and aromatic plant grown under in vitro drought stress
}

\author{
Jalil Abbaspour and Ali Akbar Ehsanpour
}

\begin{abstract}
Background: Artemisia aucheri BOISS is a medicinal and aromatic plant, which is endemic to mountainous areas of Iran and surroundings. In this study, we investigated the alleviating effects of salicylic acid (SA) pretreatment (0.01 and $0.1 \mathrm{mM}$ ) on A. aucheri under in vitro drought stress induced by 2 and 4\% polyethylene glycol (PEG/6000).

Results: Plants exposed to PEG stress showed higher levels of $\mathrm{H}_{2} \mathrm{O}_{2}, \mathrm{MDA}$ and electrolyte leakage compared with control. While SA pretreatment decreased these parameters under PEG stress significantly. The activity of CAT, POD, APX, SOD and GR positively changed with PEG and more induction in activity of antioxidant enzymes was observed in SA-pretreated plants under PEG stress. Furthermore, ASA, GSH and their redox ratios (ASC/DHA and GSH/GSSG) enhanced with SA pretreatments. Analysis of our data revealed that MDA, DHA and $\mathrm{H}_{2} \mathrm{O}_{2}$ were the best targets for SA under in vitro PEG treatment for $A$. aucheri plants.

Conclusions: Salicylic acid as a signal molecule mitigated adverse effects of PEG-simulated drought stress on $A$. aucheri under in vitro condition by improving the activity of antioxidant enzymes. In addition, protective role of SA was also related to promotion of ascorbate-glutathione cycle.
\end{abstract}

Keywords: Artemisia aucheri, Drought stress, Salicylic acid, Polyethylene glycol, Antioxidant enzyme

\section{Background}

Artemisia aucheri BOISS is a medicinal and aromatic plant belongs to Asteraceae family. There are around 500 species of Artemisia in Asia, Europe and North America and 34 species of this family are found all over Iran (Mozaffarian 2010). Artemisia aucheri is limited mostly to mountainous landscapes with high slope, sandy soils and with annual precipitation of 300-450 $\mathrm{mm}$ (Hosseini et al. 2013). Morphological features of this plant consist of perennial, suffrutescent, stem numerous and erect, indumentum white-tomentose, leaves pinnate or bipinnate, capitula arranged in a panicle-congested, calathium sessile and ovate, phyllaries imbricate and multiseriate,

\footnotetext{
${ }^{*}$ Correspondence: ehsanpou@sci.ui.ac.ir Department of Biology, Faculty of Science, University of Isfahan, Isfahan, Iran
}

florets 3-4 (Podlech 1986). This plant has many medicinal properties and is useful in traditional medicines for the treatment of some diseases. Some findings indicate that $A$. aucheri extraction have cytotoxic effects in cancer treatment (Ghazi-Khansaria et al. 2013). In addition, anti leishmanial effects of this plant have been studied (Sharif et al. 2006). Verbenone, camphor, 1,8-cineole, transverbenol, chrysanthenone, mesitylene, $\alpha$-pinene, acyclic monoterpenes, and monoterpenehydroperoxides are bioactive compounds that can be extracted from this plant (Hashemi et al. 2007; Rustaiyan et al. 1987).

Water stress is one of the major environmental stresses that limit plant growth and development around the world. Plants have advanced complex mechanisms at cellular and molecular levels to mitigate negative effects of water deficiency (Chaves et al. 2009; Shen et al. 2014). Drought stress induces generation of reactive oxygen 
species (ROS) leading to oxidative stress (Bartels and Sunkar 2005). When ROS accumulate in plant tissues, it damages lipids, proteins, DNA and consequently leading to cell death (Molassiotis et al. 2006). To alleviate the deleterious effects of ROS, plants developed an antioxidant defense system including both enzymatic such as superoxide dismutase (SOD), ascorbate peroxidase (APX), catalase (CAT), peroxidase (POD), glutathione reductase (GR), and non-enzymatic antioxidants including ascorbate and glutathione (Foyer and Noctor 2005; Gill and Tuteja 2010; Mittler 2002; Suzuki et al. 2012). It seems that the balance between ROS production and capability of scavenging ROS by antioxidant system affects on drought tolerance of plant (Boaretto et al. 2014).

Salicylic acid (SA) is a natural phenolic compound and plant growth regulator that plays a key role in the regulation of plant growth and development (RivasSan Vicente and Plasencia 2011). Previous studies have shown some roles of SA in biotic stresses via induction of systemic acquired resistance. In addition to its role in biotic stress responses, SA also participates in modulating the plant response to many abiotic stresses, including salinity (Rady and Mohamed 2015), cold (Luo et al. 2014), drought (Ying et al. 2013) and the excess of heavy metals (Shakirova et al. 2016). SA as a signal molecule increases the activity of enzymatic antioxidant and reduce the production of reactive oxygen species (ROS) (Horváth et al. 2007). It has been found that exogenously application of SA enhances both enzymatic and non-enzymatic systems under water stress and consequently improves drought resistance. Furthermore, exogenous application of SA decreased the damaging effect of drought on plants by maintaining the integrity of the plasma membrane, which evaluate by reduction of malondialdehyde (MDA) and electrolyte leakage (Kadioglu et al. 2011). However, most of the reports have focused on the roles of SA in field condition and there is little information about its role in modification of antioxidant system under in vitro condition. On the other hand, tissue culture technology is a rapid and fast method in assessment of physiological responses of plant to phytohormones, elicitors and abiotic stresses (Ramakrishna and Ravishankar 2011).

Polyethylene glycol (PEG) has been widely used to mimic drought in many studies to investigate plant adaptive mechanisms (Hajihashemi et al. 2013; He et al. 2014). Despite the relatively great number of reports on the compounds and medicinal properties of A. aucheri, there is no report on the physiological and biochemical responses of this plant to PEG as well as possible positive effects of SA treatment. Therefore, in the present study PEG-6000 and SA were used (1) to understand the effect of oxidative stress induced by water stress on $A$. aucheri
(2) to determine which physiological parameter/s is more responsive to PEG and SA as the best target.

\section{Methods \\ Plant materials and treatments}

The A. aucheri BOISS plants were obtained from Department of Biology, University of Isfahan, Isfahan, Iran. For multiplication, plants were grown on MS medium (Murashige and Skoog 1962) supplemented with $30 \mathrm{~g} \mathrm{l}^{-1}$ sucrose and $8 \mathrm{~g} \mathrm{l}^{-1}$ agar (pH 5.8) then all cultures were kept at $25 \pm 1{ }^{\circ} \mathrm{C}$ with $16 / 8 \mathrm{~h}$ photoperiod under approx. $44 \mu \mathrm{mol}$ phot $\mathrm{m}^{-2} \mathrm{~s}^{-1}$ light.

As pretreatment, in vitro grown explants were cultured on MS medium containing, $0,0.01$ and $0.1 \mathrm{mM}$ SA for 1 week, plants were then transferred to MS medium supplemented with 0, 2 and 4\% (w/v) PEG (MW 6000) for 2 weeks. PEG was added to MS medium according to diffusion based method described by Girma and Krieg (1992). The water potentials of media (MS medium supplemented with and without PEG) were: $-0.3 \mathrm{MPa}$ for control; $-0.45 \mathrm{MPa}$ for $2 \% \mathrm{PEG}$ and $-0.6 \mathrm{MPa}$ for $4 \%$ PEG.

\section{$\mathrm{H}_{2} \mathrm{O}_{2}$ content}

Hydrogen peroxide content was determined according to Velikova et al. (2000). Fresh leaves $(500 \mathrm{mg}$ ) were homogenized with $5 \mathrm{ml}$ of $0.1 \%(\mathrm{w} / \mathrm{v})$ trichloroacetic acid (TCA). The homogenate was centrifuged at $12,000 \mathrm{~g}$ for $15 \mathrm{~min}$. Then, $0.5 \mathrm{ml}$ of the supernatant was added to $0.5 \mathrm{ml} 10 \mathrm{mM}$ potassium phosphate buffer ( $\mathrm{pH} \mathrm{7.0)}$ and $1 \mathrm{ml}$ of $1 \mathrm{M}$ KI. After incubation of samples for $15 \mathrm{~min}$ at room temperature, the absorbance of samples was recorded at $390 \mathrm{~nm}$. The $\mathrm{H}_{2} \mathrm{O}_{2}$ contents were calculated using a standard curve and results were expressed as $\mu \mathrm{mol} \mathrm{g}{ }^{-1} \mathrm{FW}$.

\section{Lipid peroxidation}

Lipid peroxidation was measured by method of Heath and Packer (1968). Leaf samples (0.2 g) were homogenized in $5 \mathrm{ml}$ of trichloroacetic acid (TCA, $0.1 \% \mathrm{w} / \mathrm{v}$ ) and centrifuged at $10,000 \mathrm{~g}$ for $15 \mathrm{~min}$ at $4{ }^{\circ} \mathrm{C}$. To each $1 \mathrm{ml}$ aliquot of the supernatant, $4 \mathrm{ml}$ of $20 \%$ TCA containing $0.5 \%$ thiobarbituric acid (TBA) was added. The mixture was incubated for $30 \mathrm{~min}$ at $95{ }^{\circ} \mathrm{C}$ and then quickly cooled in an ice bath. The absorbance of the samples was recorded at 532 and $600 \mathrm{~nm}$. The malondialdehyde (MDA) content was calculated using an extinction coefficient of $155 \mathrm{mM}^{-1} \mathrm{~cm}^{-1}$ and the results expressed as nmol g ${ }^{-1} \mathrm{FW}$.

\section{Electrolyte leakage determination}

The membrane injury under PEG treatment was estimated by electrolyte leakage as described by Lutts et al. (1995) method. Leave samples (0.2 g) were placed in 
test tubes containing $10 \mathrm{ml}$ of double distilled water. Leaf discs were incubated on shaker at $25{ }^{\circ} \mathrm{C}$ for $6 \mathrm{~h}$ then electrical conductivity $\left(\mathrm{EC}_{1}\right)$ was measured. Samples were then autoclaved at $120^{\circ} \mathrm{C}$ for $20 \mathrm{~min}$ and after cooling the solution at room temperature, the final electrical conductivity $\left(\mathrm{EC}_{2}\right)$ was recorded. The electrolyte leakage $(\mathrm{EL})$ was calculated by using the following formula:

$$
\mathrm{EL}=\left(\mathrm{EC}_{1} / \mathrm{EC}_{2}\right) \times 100
$$

\section{Antioxidative enzyme activities}

To extract antioxidative enzymes, fresh leaf samples $(1 \mathrm{~g})$ were homogenized using a chilled mortar and pestle in $5 \mathrm{ml}$ of Na-phosphate buffer (100 mM, pH 7.8) containing EDTA (1 mM), dithiothreitol, (DTT, $1 \mathrm{mM}$ ) and polyvinylpyrrolidone (PVP, $2 \% \mathrm{w} / \mathrm{v})$. The homogenates were centrifuged at $13,000 \mathrm{~g}$ for $20 \mathrm{~min}$ at $4{ }^{\circ} \mathrm{C}$. The supernatant was used for the assays of antioxidative enzyme activities using UV-visible spectrophotometer (Shimadzu, Japan). Protein content was determined according to Bradford (1976), using bovine serum albumin (BSA) as standard.

Catalase activity (CAT, EC 1.11.1.6) was assayed according to the method of Aebi (1984). The reaction mixture in a total volume of $1 \mathrm{ml}$ consisted of $0.95 \mathrm{ml}$ of $50 \mathrm{mM}$ sodium phosphate buffer ( $\mathrm{pH}$ 7.0), $10 \mathrm{mM} \mathrm{H}_{2} \mathrm{O}_{2}$ and $50 \mu \mathrm{l}$ of enzyme extract. The decrease in the absorbance of $\mathrm{H}_{2} \mathrm{O}_{2}$ was recorded at $240 \mathrm{~nm}$ for $1 \mathrm{~min}$. The enzyme activity was calculated using an extinction coefficient of $39.4 \mathrm{mM}^{-1} \mathrm{~cm}^{-1}$ and expressed as $\mu \mathrm{mol}$ decomposition of $\mathrm{H}_{2} \mathrm{O}_{2} \mathrm{~min}^{-1} \mathrm{mg}^{-1}$ protein.

Peroxidase (EC 1.11.1.7) activity was measured by method of Plewa et al. (1991). The assay mixture was consisted of $1.99 \mathrm{ml} 50 \mathrm{mM}$ sodium phosphate buffer $(\mathrm{pH}$ 7.0) supplemented with $0.1 \mu \mathrm{M}$ EDTA, $10 \mathrm{mM}$ guaiacol and $15 \mathrm{mM} \mathrm{H}_{2} \mathrm{O}_{2}$ and $100 \mu \mathrm{l}$ of the enzyme extract in a total volume of $2 \mathrm{ml}$. Guaiacol oxidation and production of tetraguaiacol was monitored by increase in absorbance of $470 \mathrm{~nm}$. The activity of POD was calculated by extinction coefficient of tetraguaiacol $\left(26.6 \mathrm{mM}^{-1} \mathrm{~cm}^{-1}\right)$ and expressed as $\mu \mathrm{mol}$ tetraguaiacol $\mathrm{min}^{-1} \mathrm{mg}^{-1}$ protein.

Activity of APX (EC 1.11.1.11) was determined by recording the decrease in absorbance of ascorbate at $290 \mathrm{~nm}$ as described by Nakano and Asada (1986). The reaction mixture $(1.0 \mathrm{ml})$ contained $0.95 \mathrm{ml}$ of $50 \mathrm{mM}$ sodium phosphate buffer ( $\mathrm{pH} 7.0$ ), $0.5 \mathrm{mM}$ ascorbic acid, $0.2 \mathrm{mM}$ EDTA, $0.2 \mathrm{mM} \mathrm{H}_{2} \mathrm{O}_{2}$ and $50 \mu \mathrm{l}$ of enzyme extract. APX activity was calculated by using the extinction coefficient $2.8 \mathrm{mM}^{-1} \mathrm{~cm}^{-1}$ and expressed as $\mu \mathrm{mol}$ decomposition of ascorbate $\mathrm{min}^{-1} \mathrm{mg}^{-1}$ protein.

Superoxide dismutase (SOD, EC 1.15.1.1) activity was measured by monitoring the inhibition of the photochemical reduction of nitro blue tetrazolium (NBT) as described by Beauchamp and Fridovich (1971). The reaction mixture, consisted of $50 \mathrm{mM}$ Na-phosphate buffer (pH 7.8), $0.1 \mathrm{mM}$ EDTA, $13 \mathrm{mM}$ methionine (Sigma-Aldrich Corporation), $75 \mu \mathrm{M}$ NBT (Sigma-Aldrich Corporation), $2 \mu \mathrm{M}$ riboflavin (Sigma-Aldrich Corporation), and $50 \mu \mathrm{l}$ of enzyme extract in a test tubes, were incubated for 15 min under fluorescent. One unit of SOD activity was defined as the amount of enzyme that inhibited $50 \%$ of NBT photochemical reduction and expressed as unit $\mathrm{mg}^{-1}$ protein.

Activity of GR (EC 1.6.4.2) was determined based on the method of Smith et al. (1988). The reduction of 5,5'-dithiobis-2-nitrobenzoic acid (DTNB) to TNB was measured by reduced glutathione (GSH). The reaction mixture $(1.0 \mathrm{ml})$ consisted of $0.980 \mathrm{ml}$ of $50 \mathrm{mM}$ potassium phosphate buffer ( $\mathrm{pH}$ 7.5), $0.5 \mathrm{mM}$ EDTA, $0.75 \mathrm{mM}$ DTNB (Sigma-Aldrich Corporation), $0.1 \mathrm{mM}$ NADPH (SigmaAldrich Corporation), $1 \mathrm{mM}$ oxidized glutathione (GSSG) (Sigma-Aldrich Corporation) and $0.01 \mathrm{ml}$ of the enzyme extract. The rate of increase in the absorbance of $412 \mathrm{~nm}$ was recorded for $1 \mathrm{~min}$. The enzyme activity was calculated using an extinction coefficient of $6.2 \mathrm{mM}^{-1} \mathrm{~cm}^{-1}$ and expressed as $\mu \mathrm{mol}$ of TNB $\mathrm{min}^{-1} \mathrm{mg}^{-1}$ protein.

\section{Ascorbate and glutathione contents}

Estimation of the ascorbate (ASC), dehydroascorbate (DHA) and total ascorbate was performed by method of Law et al. (1983). Fresh leaf samples $(0.2 \mathrm{~g})$ were homogenized in $2 \mathrm{ml}$ of $6 \%(\mathrm{w} / \mathrm{v})$ trichloroacetic acid (TCA) using a chilled mortar and pestle and centrifuged at $15,000 \mathrm{~g}$ for $15 \mathrm{~min}$ at $4{ }^{\circ} \mathrm{C}$. To estimate the total ascorbate, $200 \mu \mathrm{l}$ of $150 \mathrm{mM}$ Na-phosphate buffer (pH 7.4) and $200 \mu \mathrm{l}$ of $10 \mathrm{mM}$ DTT were added to $200 \mu \mathrm{l}$ of the supernatant. The mixture was incubated at room temperature for $10 \mathrm{~min}$, then mixed with $100 \mu \mathrm{l}$ of $0.5 \% \mathrm{~N}$-ethylmaleimide (NEM). ASC content was determined in the same way, except that DTT and NEM were replaced with water. To each of samples were then added $400 \mu \mathrm{l}$ of $10 \%(\mathrm{w} / \mathrm{v})$ TCA, $400 \mu \mathrm{l}$ of $44 \%(\mathrm{v} / \mathrm{v}) \mathrm{H}_{3} \mathrm{PO}_{4}, 400 \mu \mathrm{l}$ of $4 \%(\mathrm{w} / \mathrm{v}) \alpha$ - $\alpha^{\prime}$-bipyridyl dissolved in $70 \%$ ethanol and $200 \mathrm{ml}$ of $3 \% \mathrm{FeCl}_{3}$. After shaking, samples were incubated at $37{ }^{\circ} \mathrm{C}$ for $60 \mathrm{~min}$ and absorbance was recorded at $525 \mathrm{~nm}$ on a UV-Vis Spectrophotometer (Shimadzu, Japan). The difference between the total ascorbate and ASC content was used to calculate DHA content. The concentrations of total ascorbate and ASC were calculated using a standard curve with known amount of ASC and expressed in $\mu \mathrm{mol} \mathrm{g} \mathrm{g}^{-1} \mathrm{FW}$.

To extract glutathione, fresh leaves $(0.2 \mathrm{~g})$ were homogenized in $2 \mathrm{ml}$ of $5 \%(\mathrm{w} / \mathrm{v})$ sulphosalicylic acid using a chilled mortar and pestle. The homogenate was centrifuged at $10,000 \mathrm{~g}$ for $10 \mathrm{~min}$ at $4{ }^{\circ} \mathrm{C}$ and supernatant was used for estimation of reduced (GSH), oxidised (GSSG) and total glutathione according to Anderson (1985) method. Total glutathione (GSH + GSSG) was measured using an assay 
mixture containing $143 \mathrm{mM}$ sodium phosphate buffer $(\mathrm{pH}$ 7.5), $6.3 \mathrm{mM}$ EDTA, $0.3 \mathrm{mM} \mathrm{NADPH}$ and $150 \mu \mathrm{l}$ of the supernatant, in total volume $0.85 \mathrm{ml}$. To estimate GSSG content, before adding this buffer, $10 \mu \mathrm{l}$ of 2-vinylpyridine and $20 \mu \mathrm{l}$ of triethanolamine mixed with 150 supernatant. Then, $100 \mu \mathrm{l}$ of DTNB $(6 \mathrm{mM})$ and five unit of glutathione reductase were added and the absorbance of samples were recorded at 412 after $5 \mathrm{~min}$. Total glutathione and GSSG were determined using a standard curve prepared using GSH. The amount of GSH was calculated as the difference between total glutathione and GSSG.

\section{Statistical analysis}

All experiments were performed with at least three independent replicates. Data were analyzed for significance of differences between means with Duncan's test at $\mathrm{P}<0.05$ (Two-way ANOVA). SPSS software (version 16) was used for Statistical analysis of data and results were expressed as mean \pm standard deviation (SD). The standardization of values was also carried out by SPSS software using the following formula.

$$
z_{i}=\frac{X_{i}-\bar{X}}{S}
$$

$\mathrm{X}_{\mathrm{i}}=$ each data point $\mathrm{i}, \mathrm{X}=$ the average of all the sample data points, $S=$ the sample standard deviation of all sample data points, $\mathrm{z}_{\mathrm{i}}=$ the data point $\mathrm{i}$ standardized to $\mathrm{s}$, also known as Z-score.

\section{Results}

$\mathrm{H}_{2} \mathrm{O}_{2}$ content, lipid peroxidation and electrolyte leakage

$\mathrm{H}_{2} \mathrm{O}_{2}$ level of pretreated plant with $0.1 \mathrm{mM} \mathrm{SA}$ was significantly higher than control plants, without PEG stress. Increasing of PEG concentration induced a dramatic increase in $\mathrm{H}_{2} \mathrm{O}_{2}$ production. SA pretreatments had a positive effect in reduction of $\mathrm{H}_{2} \mathrm{O}_{2}$ content under 2 and 4\% PEG compared with plants without SA pretreatment (Fig. 1A). Malondialdehyde (MDA) content and electrolyte leakage was measured as an index of injury to plasma membrane under stress condition. Data showed that MDA content significantly enhanced in PEG-treated plants as highest increase was observed in 4\% PEG. In plants pretreated with SA $(0.01$ and $0.1 \mathrm{mM})$, MDA content significantly decreased under the drought Stress (Fig. 1B). Electrolyte leakage had the similar trend with MDA content as it significantly elevated by PEG and decreased in SA pretreated plants. SA pretreatment had no significant effect on MDA content and electrolyte leakage of control plant without PEG stress (Fig. 1B, C).

\section{Antioxidative enzyme activities}

Increase of antioxidant enzymes such as CAT, APX, POD, SOD and GR is one of the most common defense responses of plants against oxidative. As shown in Fig. 2, SA pretreatment induced activity of all antioxidant enzymes under PEG stress. In the presence of SA, CAT activity significantly declined in control plant without PEG treatment. Artemisia aucheri plants showed more CAT activity at $4 \%$ PEG but not at $2 \%$ compared with control plants. Pretreatments of SA $(0.01$ and $0.1 \mathrm{mM})$ induced the higher CAT activities than PEG treatments without SA (Fig. 2A). Water stress resulting from PEG significantly increased activity of APX in both levels of PEG. SA pretreatment had no effect on in control and plant treated with $2 \%$ PEG, but SA significantly improved APX activity under high level of PEG (Fig. 2C). Similar to CAT, pretreatments with 0.01 and $0.1 \mathrm{mM}$ SA significantly reduced POD activity in control plant without PEG treatment and lower activity was observed at $0.01 \mathrm{mM}$ SA. Plants subjected to 2 and 4\% PEG demonstrated similar increase in activity of POD compared with the control. Under $2 \%$ PEG, the plant pretreated with $0.1 \mathrm{mM}$ SA showed higher POD activity, while $0.01 \mathrm{mM}$ SA had no significant effect. In the presence of $4 \%$ PEG, the POD activity noticeably enhanced with SA pretreatments and culminated at $0.1 \mathrm{mM}$ SA (Fig. 2B). The exposure of $A$. aucheri to PEG significantly increased SOD almost based on a PEG concentration dependent manner. The effectiveness of SA pretreatment in increasing SOD activity was only observed at $0.01 \mathrm{mM}$ SA. Moreover, activity of SOD in untreated as well as pretreated plants was not different in the absence of PEG (Fig. 2D). Plant grown with 2 and 4\% PEG demonstrated higher levels of GR activity compared with control plants. SA pretreatment plus PEG increased GR activity more than PEG without SA and the effect of both concentrations of SA was almost the same. However, SA pretreatment had no significant effect on GR activity under normal condition (Fig. 2E). In the present study, it is interesting that, positive effects of SA on some antioxidant enzymes under the same PEG levels were similar and not depending on the SA concentration.

\section{Ascorbate and glutathione contents}

The effects of drought and SA pretreatments on ascorbate and glutathione pools of $A$. aucher $i$ are illustrated in Figs. 3 and 4. In the absence of PEG, SA pretreatment at $0.01 \mathrm{mM}$ increase ASC and ASC/DHA ratio significantly. A similar pattern was obtained in ASC content and ASC/ DHA ratio under both concentrations of PEG. By contrast, DHA content showed similar increase in 2 and $4 \%$ PEG. In comparison with $2 \%$ PEG, SA pretreatments plus 2\% PEG significantly enhanced ASC content and ASC/ DHA in dose dependent manner but decreased DHA content. In addition, plant subjected to $4 \%$ PEG and SA pretreatments $(0.01$ and $0.1 \mathrm{mM})$ showed higher ASC content and ASC/DHA ratio against 4\% PEG without SA 

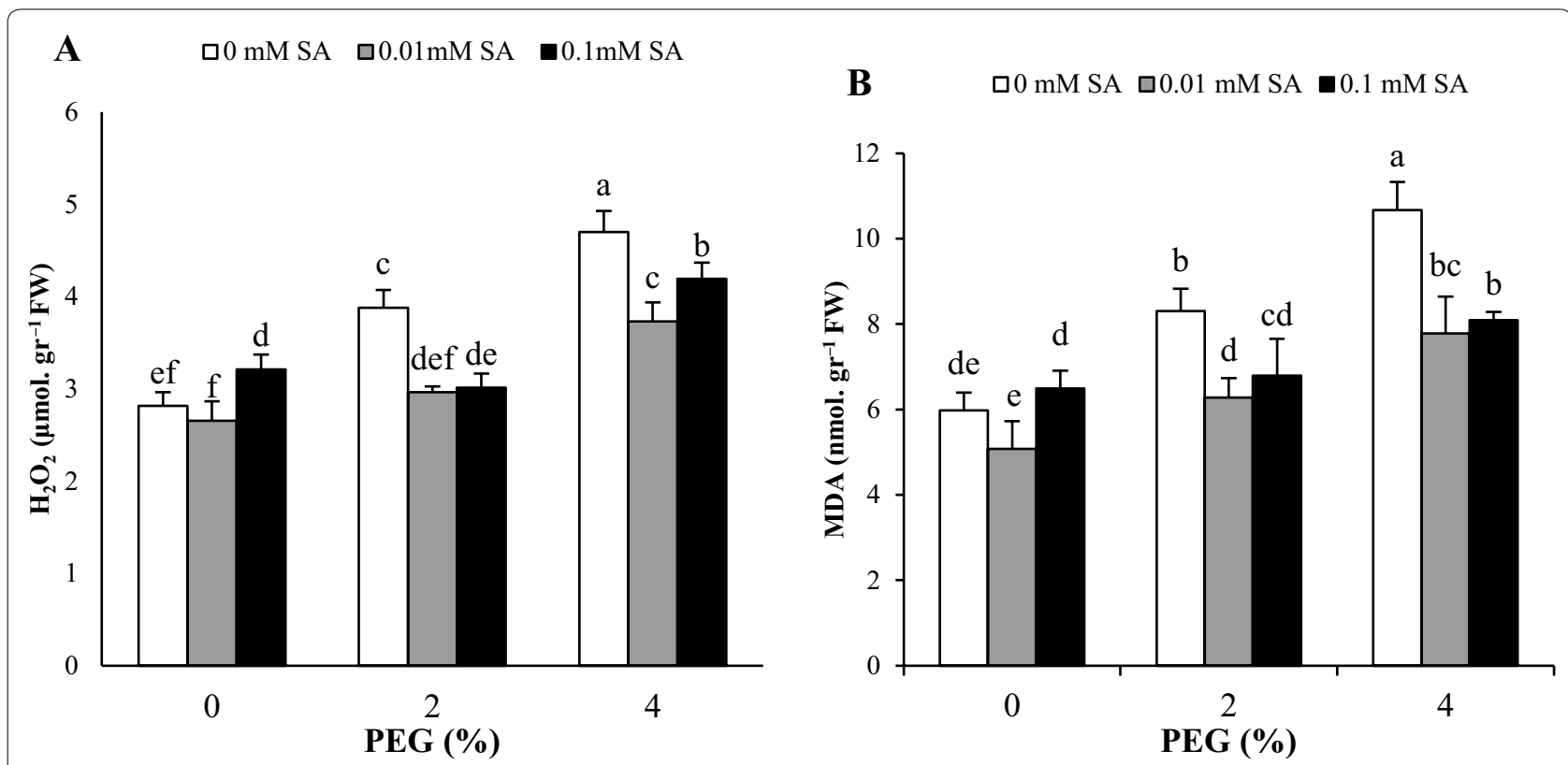

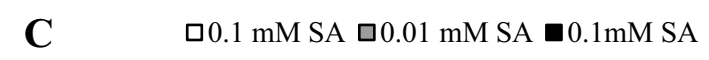

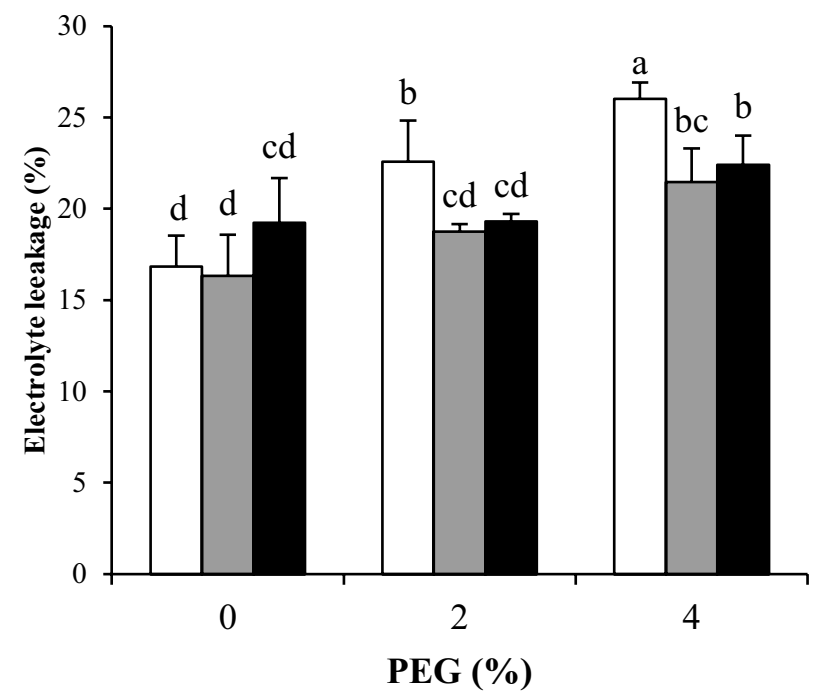

Fig. 1 Effects of SA pretreatment and PEG on $\mathbf{A ~} \mathrm{H}_{2} \mathrm{O}_{2}$, B MDA content and $\mathbf{C}$ electrolyte leakage of Artemisia aucheri. Data are mean \pm SD of three replicates $(n=3)$. Different letters indicate significant $(P<0.05)$ based on Duncan's test

pretreatments, but there was no difference at 0.01 and $0.1 \mathrm{SA}$. The values of total ascorbate weren't affected by PEG-simulated drought stress and SA pretreatment.

Under non-stress condition, glutathione pools did not change with SA pretreatments, except for GSH/ GSSG which increased with $0.01 \mathrm{mM}$ SA. GSH content and GSH/GSSG ratio decreased gradually with increasing of PEG concentrations. Combination of SA pretreatments at 0.01 and $0.1 \mathrm{mM}$ in the medium with $2 \%$ PEG increased GSH content and GSH/GSSG ratio equally compared to $2 \%$ PEG without SA pretreatments. In contrast, a similar decrease was observed in GSSG content by $2 \%$ PEG plus 0.01 and $0.1 \mathrm{mM}$ SA compared with $2 \%$ PEG without SA pretreatments. In plants treated with $4 \%$ PEG, SA pretreatment caused a decrease in GSSG content in a dose-dependent manner. The opposite trend was found in GSH content and GSH/GSSG ratio. Total glutathione reduced under PEG stress and maximum reduction was observed at high level of PEG (4\%), but SA had no alleviating effect on total glutathione (Fig. 4). 
A

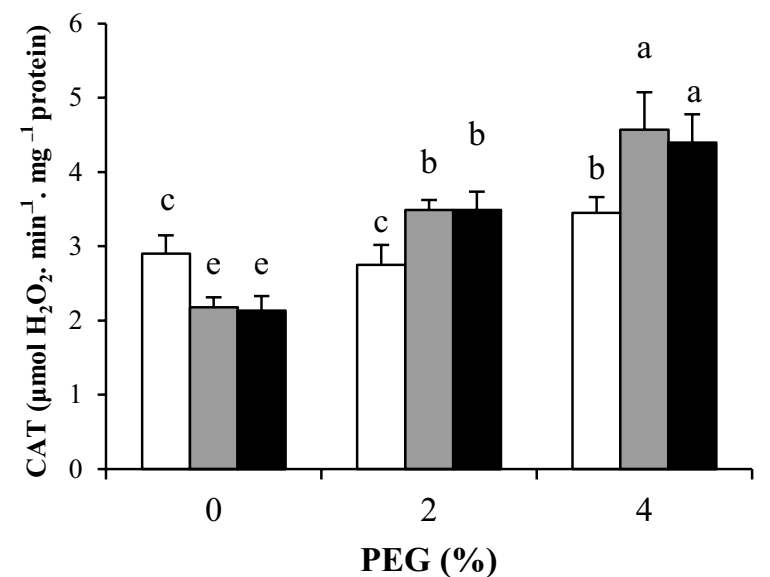

C

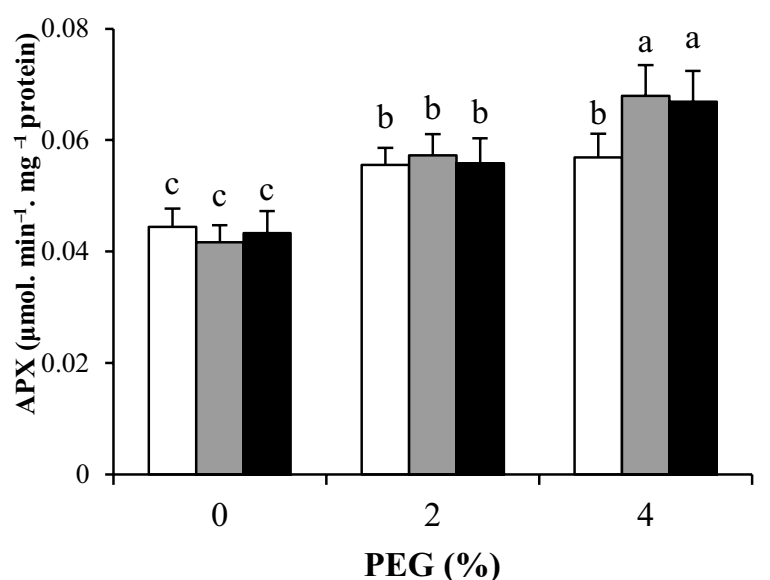

B

$\square 0 \mathrm{mMSA} \quad \square 0.01 \mathrm{mMSA} \quad \mathbf{0} 0.1 \mathrm{mMSA}$

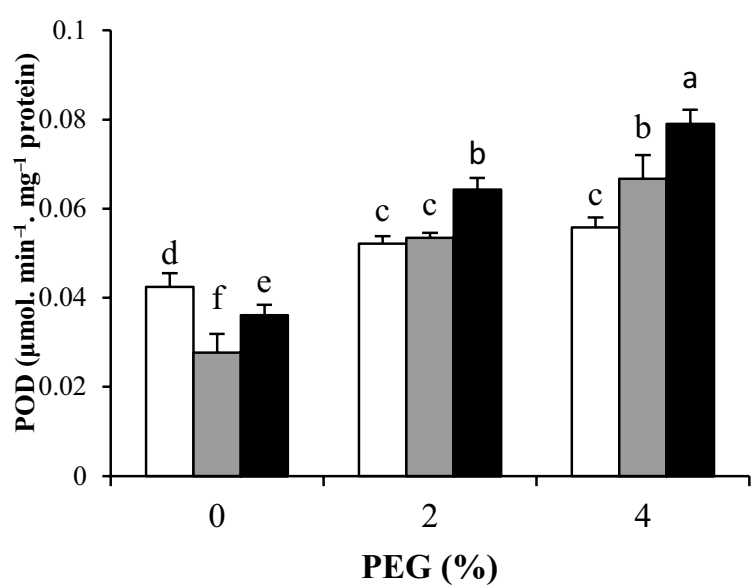

D $\square 0 \mathrm{mMSA} \quad \square 0.01 \mathrm{mMSA} \quad 0.1 \mathrm{mMSA}$

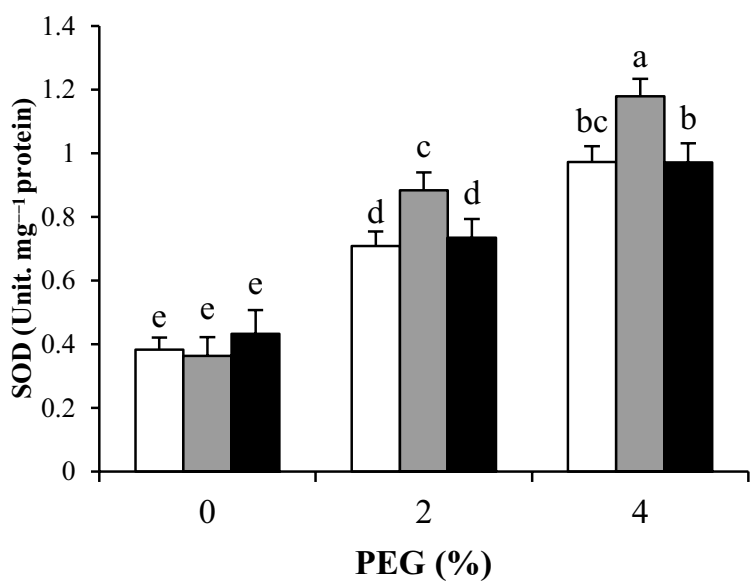

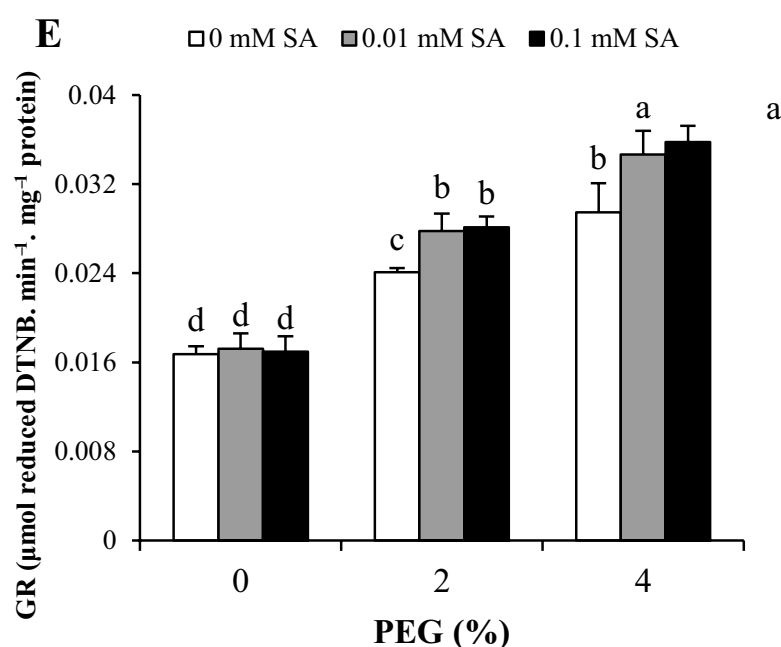

Fig. 2 Effects of SA pretreatment and PEG on activities of A CAT, B POD, C APX, D SOD and E GR of Artemisia aucheri. Data are mean \pm SD of three replicates $(n=3)$. Different letters indicate significant $(P<0.05)$ based on Duncan's test 

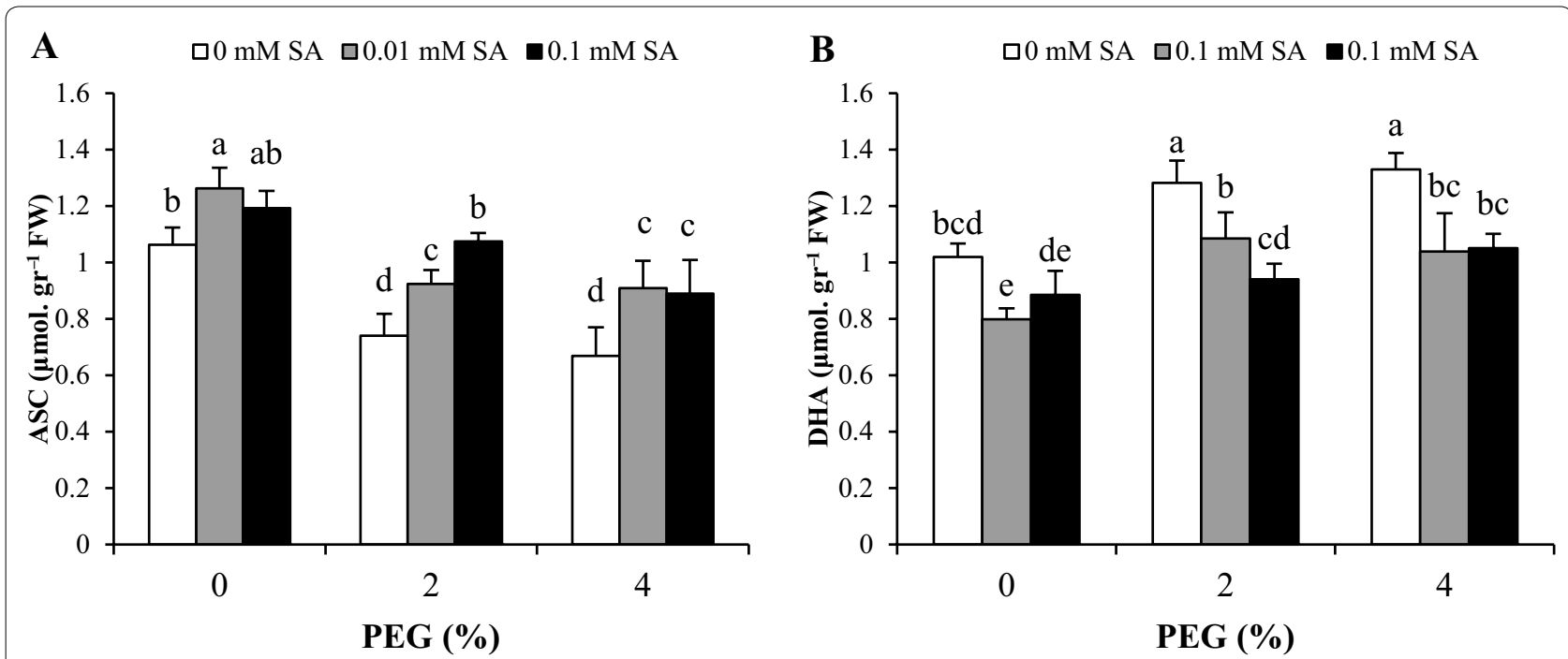

C $\quad \square 0 \mathrm{mMSA} \square 0.01 \mathrm{mM} \mathrm{SA} \square 0.1 \mathrm{mMSA}$

$\mathbf{D}$
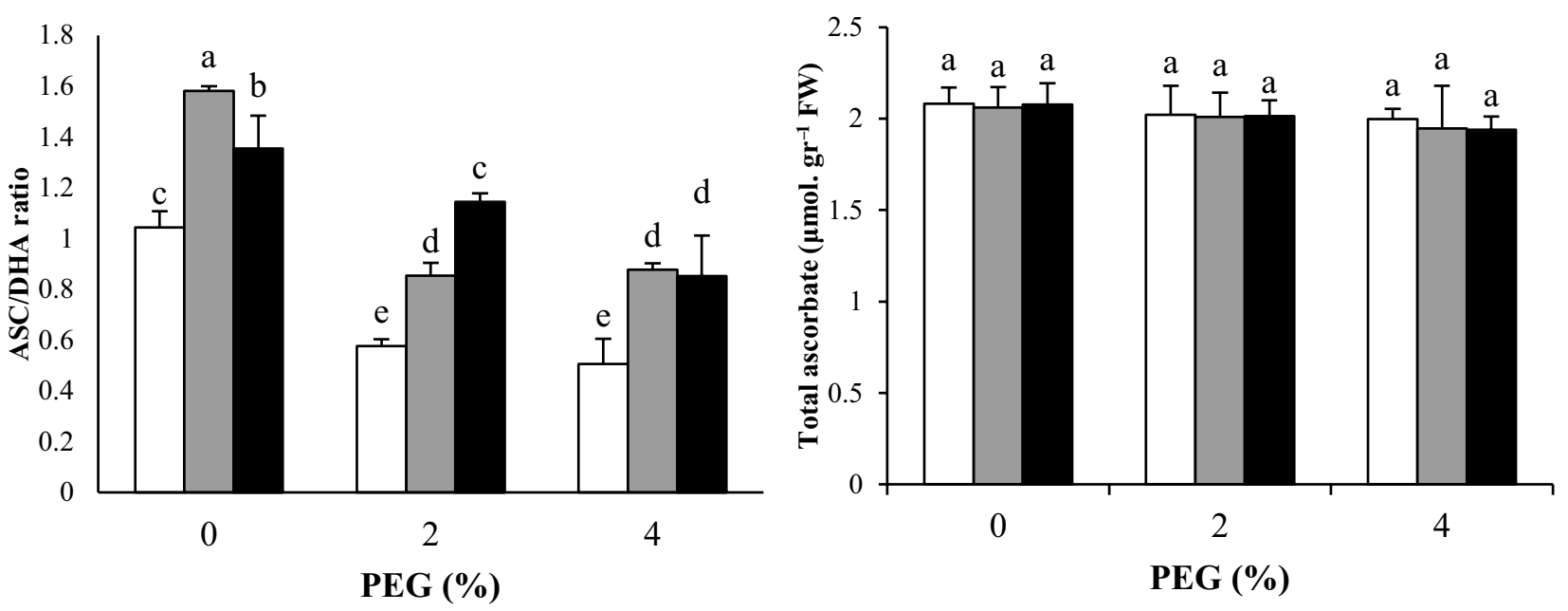

Fig. 3 Effects of SA pretreatment and PEG on A ASC, B DHA, C ASC/DHA ratio and D total ascorbate of Artemisia aucheri. Data are mean \pm SD of three replicates $(n=3)$. Different letters indicate significant $(P<0.05)$ based on Duncan's test

\section{Comparing of biochemical indicators based on standardization of their values}

To identify the best biochemical targets for SA and PEG treatment in $A$. aucheri plants, we standardized the data obtained from different biochemical measurements (Table 1) based on the Z-score of the variables. According to Table 1, the comparison of standard values indicated $\mathrm{SA}$ at 0.01 and $0.1 \mathrm{mM}$ (in control without PEG treatments) positively affected ASC/DHA ratio more than other parameters. PEG stress at 2 and $4 \%$ alone showed maximum negative effect on GSH/GSSG and GSSG, respectively. The interaction of $0.01 \mathrm{mM}$ SA with $2 \%$ PEG had a maximum effect in decreasing of $\mathrm{H}_{2} \mathrm{O}_{2}$ compared to the other indicators, while interaction of $0.1 \mathrm{mM} \mathrm{SA}$ with both concentrations of PEG was more effective on decreasing of DHA. Furthermore, the reduction of MDA content under 4\% PEG with $0.1 \mathrm{mM}$ SA was more noticeable compared to other biochemical indicators (Table 1).

\section{Discussion}

Under drought stress, plant display some physiological and biochemical responses to cope with oxidative damage. These responses include enzymatic and nonenzymatic defense systems leading to stress tolerance. Increasing evidences show that phytohormones play an important role in drought tolerance. Salicylic acid is one of the important plant growth regulators which has a critical role in modulating responses to drought (Kang 


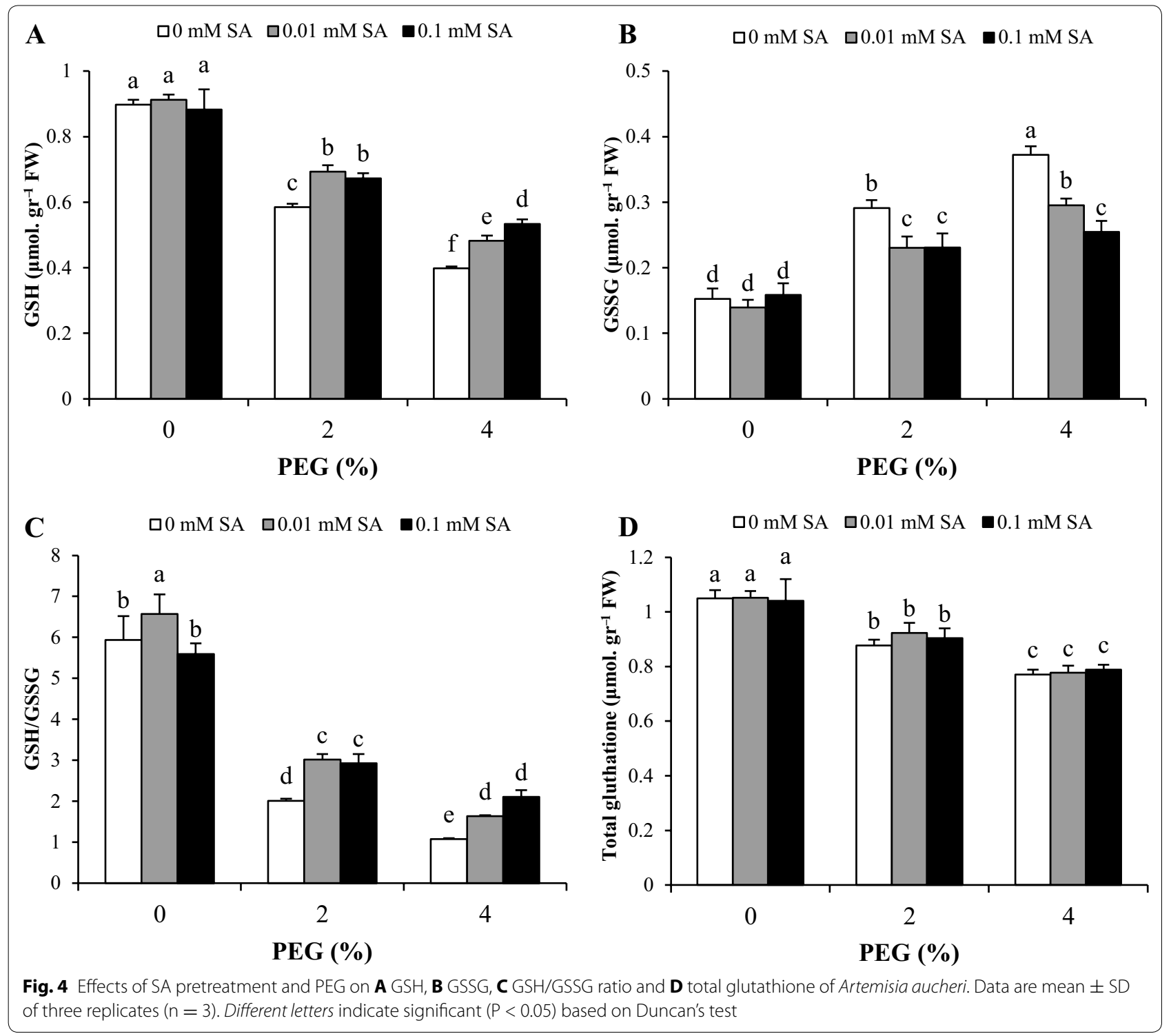

Table 1 Biochemical targets of SA pretreatment and PEG on Artemisia aucheri by comparing of standard values in each row (marked by circle) based on Z-score of the variables

\begin{tabular}{cccccccccccccccccc}
\hline PEG (\%) & SA (mM) & $\mathbf{H}_{2} \mathbf{O}_{2}$ & MDA & IL & CAT & POD & APX & SOD & GR & ASC & DHA & $\begin{array}{c}\text { ASC } \\
\text { IDHA }\end{array}$ & $\begin{array}{c}\text { Total } \\
\text { ASC }\end{array}$ & $\begin{array}{c}\text { GSH } \\
\text { GSSG }\end{array} \begin{array}{c}\text { GSH } \\
\text { /GSSG }\end{array} \begin{array}{c}\text { Total } \\
\text { GIn }\end{array}$ \\
\hline 0 & 0 & -0.944 & -0.779 & -1.064 & -0.419 & -0.682 & -1.009 & -1.240 & -1.234 & 0.464 & -0.162 & 0.197 & 0.549 & 1.216 & -1.110 & 1.259 & 1.202 \\
& 0.01 & -1.176 & -1.322 & -1.215 & -1.254 & -1.631 & -1.289 & -1.307 & -1.164 & 1.465 & -1.404 & 1.776 & 0.381 & 1.299 & -1.280 & 1.580 & 1.224 \\
& 0.1 & -0.364 & -0.468 & -0.335 & -1.308 & -1.090 & -1.125 & -1.067 & -1.201 & 1.111 & -0.916 & 1.110 & 0.516 & 1.135 & -1.030 & 1.087 & 1.126 \\
2 & 0 & 0.609 & 0.618 & 0.686 & -0.595 & -0.058 & 0.112 & -0.099 & -0.217 & -1.144 & 1.323 & -1.176 & 0.044 & -0.476 & 0.732 & -0.713 & -0.279 \\
& 0.01 & -0.724 & -0.597 & -0.476 & 0.261 & 0.023 & 0.288 & -0.515 & 0.295 & -0.222 & 0.214 & -0.359 & -0.056 & 0.107 & -0.075 & -0.208 & 0.121 \\
& 0.1 & -0.654 & -0.287 & -0.312 & 0.265 & 0.721 & 0.144 & -0.004 & 0.345 & 0.523 & -0.606 & 0.491 & -0.022 & -0.001 & -0.068 & -0.252 & -0.046 \\
4 & 0 & 1.804 & 2.040 & 1.735 & 0.219 & 0.172 & 0.248 & 0.829 & 0.528 & -1.497 & 1.589 & -1.382 & -0.157 & -1.490 & 1.804 & -1.185 & -1.186 \\
& 0.01 & 0.389 & 0.307 & 0.348 & 1.516 & 0.877 & 1.363 & 1.550 & 1.249 & -0.300 & -0.051 & -0.291 & -0.594 & -1.035 & 0.784 & -0.902 & -1.1286 \\
& 0.1 & 1.061 & 0.488 & 0.634 & 1.314 & 1.669 & 1.262 & 0.823 & 1.404 & -0.399 & 0.014 & -0.366 & -0.661 & -0.755 & 0.245 & -0.666 & -1.033 \\
\hline
\end{tabular}

Circle indicates the maximum difference with the same level of PEG treatment. Positive values indicate data above, and negative values shows data below the average (zero). Data are mean of three replicates 
et al. 2014; Miura and Tada 2014). To understand the possible positive effects of SA pretreatment during PEG stress, we investigated this plant hormone on $A$. aucheri under PEG treatment in in vitro condition.

Our results indicated PEG-simulated drought stress increased $\mathrm{H}_{2} \mathrm{O}_{2}$ generation in $A$. aucheri plant. Similarly, SA pretreatment at $0.1 \mathrm{mM}$ concentration caused $\mathrm{H}_{2} \mathrm{O}_{2}$ accumulation in normal condition, while SA at both concentrations reduced the production of $\mathrm{H}_{2} \mathrm{O}_{2}$ in PEG treated $A$. aucheri plants. According to previous studies, increasing of $\mathrm{H}_{2} \mathrm{O}_{2}$ content was predictable because PEG-simulated drought stress induces oxidative stress by generation of reactive oxygen species (Hajihashemi et al. 2013; Li et al. 2011). Moreover, reduction in the $\mathrm{H}_{2} \mathrm{O}_{2}$ accumulation by application of salicylic acid under water stress has been previously reported in other plants (Nazar et al. 2015). By contrast, it has been proved SA as a signal molecule accumulated low levels of $\mathrm{H}_{2} \mathrm{O}_{2}$ (Harfouche et al. 2008). Therefore, it seemed that the increase in $\mathrm{H}_{2} \mathrm{O}_{2}$ content with $0.1 \mathrm{mM}$ SA pretreatment in non-stress condition (without PEG treatment) associated with dual role of this signal molecule to induction of drought resistance (Miura and Tada 2014). In addition, SA at $0.01 \mathrm{mM}$ was more effective than $0.1 \mathrm{mM}$ in $\mathrm{H}_{2} \mathrm{O}_{2}$ reduction under high level of PEG show in that the effectiveness of low concentration in vitro condition. Electrolyte leakage and malondialdehyde (MDA) content are indicators that reflect the degree of membrane injury. In our study, increase of PEG stress enhanced these parameters in parallel with $\mathrm{H}_{2} \mathrm{O}_{2}$ content, whereas SA pretreatments successfully ameliorated these negative effects. Membrane damage in stress condition is correlated with high $\mathrm{H}_{2} \mathrm{O}_{2}$ levels, which increase lipid peroxidation and membrane permeability (Mittler 2002). The decrease in electrolyte leakage and MDA content by SA pretreatment can be related to the promotion of antioxidant defense system and also to the lower levels of $\mathrm{H}_{2} \mathrm{O}_{2}$ in presence of SA under PEG stress. Our findings are consistent with those reported by other authors (Feng et al. 2003; Ying et al. 2013).

Antioxidative enzyme activities plays vital roles in drought tolerance by reduction of ROS. Exposure of $A$. aucheri plant to PEG led to increase with some variation in antioxidative enzyme activity including CAT, APX, POD, SOD and GR. The present results are also supported by previous observations in several plant species such as cucumber (Li et al. 2011), alfalfa (Wang et al. 2009), Kentucky bluegrass (Bian and Jiang 2009) and cotton (Sekmen et al. 2014). SOD catalyzes the conversion of superoxide radicals to $\mathrm{O}_{2}$ and $\mathrm{H}_{2} \mathrm{O}_{2}$, while CAT, POD and APX catalyze dismutation reactions of $\mathrm{H}_{2} \mathrm{O}_{2}$ into $\mathrm{H}_{2} \mathrm{O}$ (Mittler 2002). In this study, SA pretreatments positively changed antioxidative enzyme activities compared to non SA-pretreated plants under PEG stress. In case of CAT, APX and GR, similar increase was obtained at two SA concentrations, while it was different to the other enzymes. It seemed that SA had no effect on APX activity under low level of PEG (2\%) but it was effective in $4 \%$ PEG. This result may indicate that the increase in APX activity without SA have been sufficient to cope with oxidative stress under low PEG stress, while SA has improved CAT activity in this condition due to low activity. Under PEG stress, SA at $0.01 \mathrm{mM}$ concentration stimulated SOD activity while POD enzyme was induced by $0.1 \mathrm{mM}$ SA pretreatment. It probably reflects different influences on SOD and POD activity under in vitro condition. Generally, Positive effects of SA pretreatment on antioxidant enzymes in this study is in accordance with the findings obtained in sensitive and tolerant maize cultivars to drought (Saruhan et al. 2012). Furthermore, it has been previously reported that SA alleviates drought stress by induction of antioxidant enzymes such as CAT, APX, SOD, POD and GR (Habibi 2012; Kadioglu et al. 2011). It seemed that the increase of antioxidative enzyme activities by SA pretreatment, as a potential mechanism against water deficiency, promoted the ability of $A$. aucheri in ROS scavenging and resulting in a better resistance to PEG stress. Notably, our results also revealed that SA pretreatments inhibited CAT and POD activity in non-stressed condition. It has been proved that SA prevented CAT and POD activities and increased ROS accumulation (Horváth et al. 2002; Khokon et al. 2011). On the other hand, SA pretreatment with temporary inhibition of CAT and POD led to increase of $\mathrm{H}_{2} \mathrm{O}_{2}$ level in A. aucheri. $\mathrm{H}_{2} \mathrm{O}_{2}$, as a signal molecule, induced an adapting mechanism by activation of antioxidative enzymes in PEG condition leading to stress resistance. Additionally, our data indicated that plant exposed to 2\% PEG without SA exhibited higher APX activity without significant change in activity of CAT which could be explained by differences in affinity for $\mathrm{H}_{2} \mathrm{O}_{2}$ as substrate of CAT and APX. On the other hand, the $\mathrm{H}_{2} \mathrm{O}_{2}$ content in plants grown in 2\% PEG only is sufficient to increase APX activity because this enzyme has high affinity with $\mathrm{H}_{2} \mathrm{O}_{2}$. Unlike APX, CAT has low affinity with $\mathrm{H}_{2} \mathrm{O}_{2}$, thereby only removing the high concentration of $\mathrm{H}_{2} \mathrm{O}_{2}$ (Willekens et al. 1997). Noticeably, both concentrations of SA had similar effects on some antioxidant enzymes as targets under the same levels of in vitro PEG treatment.

The ascorbate-glutathione cycle is one of essential mechanism to eliminate ROS in plant exposed to stress (Drążkiewicz et al. 2003). APX and GR are two key enzymes involved in this pathway. The reduction of oxidized glutathione (GSSG) to reduce form (GSH) is mediated by the activity of GR (Noctor and Foyer 1998). Under PEG stress, our data revealed a decrease 
in reduced forms of ascorbate (ASC) and glutathione (GSH), resulting in a decrease in ASC/DHA and GSH/ GSSG ratio, particularly in plants grown at $4 \%$ PEG compared to control plants. The opposite trend was observed in DHA and GSSG content. These changes could be the result of ROS accumulation caused by PEG stress. Furthermore, elevated APX activity under PEG stress needs ASC as electron donor to produce DHA. It can be speculated that, based on the ascorbate-glutathione cycle, in addition to APX activity, the activity of GR and DHAR is effective on ASA and DHA and other components of this cycle. ASA as a substrate for APX activity is product of dehydroascorbatereductase (DHAR), where DHA is converted to ASA. Consequently, the changes of ASA and DHA under PEG stress and SA pretreatment might be related to DHAR activity while, APX activity is more correlated to changes of $\mathrm{H}_{2} \mathrm{O}_{2}$ content. Diminished GSH content with PEG may be the result of DHA reduction by enhanced dehydroascorbatereductase (DHAR) activity under oxidative stress and increasing of GR activity could not alleviate this reduction. In addition to, it proves with the decreased levels of total glutathione in present of PEG. Similar to our observations, it has been found that PEG reduces ASC, GSH and their redox ratios (ASC/DHA and GSH/GSSG) in tolerant and sensitive rice seedlings (Pyngrope et al. 2013). Pretreatment of A. aucheri with SA resulted in enhanced levels of ASC and GSH under PEG stress condition. SA also raised ASC/DHA and GSH/GSSG ratio, while DHA and GSSG contents were reduced. Furthermore, our data showed the beneficial effect of $0.1 \mathrm{mM}$ SA pretreatment compared with $0.01 \mathrm{mM}$. Similar results were obtained by Kadioglu et al. (2011) in Ctenanthe setosa GSH and ASC as a low molecular weight antioxidants contribute in activation of various defense and involve in scavenger of ROS (Gill and Tuteja 2010; Szalai et al. 2009). Moreover, it is known that maintaining of sustained level of GSH is necessary to cope with oxidative stress (Pyngrope et al. 2013). These findings suggested that SA with promotion of GR activity increased GSH content under stress condition due to conversion of GSSG to GSH (Kadioglu et al. 2011; Nazar et al. 2011). Since ASC is a substrate for APX activity, SA pretreatment raised the ASC/DHA ratio and modulated antioxidant capacity for ROS scavenging to meet the challenge of oxidative stress under drought. Our data suggest that SA improves the tolerance of A. aucheri to PEG-simulated drought Stress by enzymes and metabolites of the ascorbate-glutathione cycle. Our results demonstrated that, the total ascorbate was stable under PEG stress and SA treatment. In fact, PEG and SA changed components of ascorbate pool (ASA and DHA) not the total ascorbate, resulted in change of redox ratios (ASC/DHA and GSH/GSSG). In contrast, total glutathione progressively reduced with increase of PEG concentration, which showed destructive effects of PEG on glutathione biosynthesis.

The comparison of measured biochemical indicators in this study showed that the change of ASC/DHA ratio is a suitable indicator to assess the positive effect of SA on untreated plants with PEG. According to our results, the increase of GSH/GSSG ratio and GSSG content in A. aucheri plant treated with PEG were two suitable indicators to determine adverse effect of PEG. Since SA, strongly reduced $\mathrm{H}_{2} \mathrm{O}_{2}$, DHA and MDA content, we suggest evaluation of these biochemical parameters are the best indicators for drought stress tolerance of $A$. aucheri after SA treatment.

\section{Conclusions}

In summary, exposure of $A$. aucheri plant to drought stress induced $\mathrm{H}_{2} \mathrm{O}_{2}$, MDA, electrolyte leakage and elevated the activity of CAT, POD APX, SOD and GR. SA pretreatment at 0.1 and $0.01 \mathrm{mM}$ SA before the onset of PEG stress efficiently decreased $\mathrm{H}_{2} \mathrm{O}_{2}$, MDA and electrolyte leakage. Alleviating effects of SA pretreatments in A. aucheri plant exposed to PEG could be associated with the promotion of antioxidative enzyme activities and ascorbate-glutathione cycle resulted in tolerance to PEG stress. In addition, the changes of $\mathrm{H}_{2} \mathrm{O}_{2}$, DHA and MDA content reflected positive effect of SA pretreatment in PEG stress condition rather than other indicators.

\section{Abbreviations}

ROS: reactive oxygen species; $\mathrm{H}_{2} \mathrm{O}_{2}$ : hydrogen peroxide; MDA: malondialdehyde; CAT: catalase; POD: peroxidase; APX: ascorbate peroxidase; SOD: superoxide dismutase; GR: glutathione reductase; ASA: ascorbate; DHA: dihydroxyascorbate; GSH: reduced glutathione; GSSG: oxidized glutathione.

\section{Authors' contributions}

AAE designed and provided material of research. JA accompanied design of experiments and performed the experiments, analyze of data and wrote the manuscript. AAE read and revised the manuscript. Both authors read and approved the final manuscript.

\section{Acknowledgements}

Authors are grateful to the University of Isfahan and Plant Stress Center of Excellence (PSCE) for their support.

\section{Competing interests}

The authors declare that they have no competing interests.

Received: 12 October 2016 Accepted: 22 November 2016 Published online: 08 December 2016

\section{References}

Aebi H (1984) [13] Catalase in vitro. Methods Enzymol 105:121-126 Anderson ME (1985) Determination of glutathione and glutathione disulfide in biological samples. Methods Enzymol 113:548 
Bartels D, Sunkar R (2005) Drought and salt tolerance in plants. Crit Rev Plant Sci 24:23-58

Beauchamp C, Fridovich I (1971) Superoxide dismutase: improved assays and an assay applicable to acrylamide gels. Anal Biochem 44:276-287

Bian S, Jiang Y (2009) Reactive oxygen species, antioxidant enzyme activities and gene expression patterns in leaves and roots of Kentucky bluegrass in response to drought stress and recovery. Sci Hortic 120:264-270

Boaretto LF, Carvalho G, Borgo L, Creste S, Landell MG, Mazzafera P, Azevedo RA (2014) Water stress reveals differential antioxidant responses of tolerant and non-tolerant sugarcane genotypes. Plant Physiol Biochem 74:165-175

Bradford MM (1976) A rapid and sensitive method for the quantitation of microgram quantities of protein utilizing the principle of protein-dye binding. Anal Biochem 72:165-175

Chaves M, Flexas J, Pinheiro C (2009) Photosynthesis under drought and salt stress: regulation mechanisms from whole plant to cell. Ann Bot 103:551-560

Drążkiewicz M, Skórzyńska-Polit E, Krupa Z (2003) Response of the ascorbateglutathione cycle to excess copper in Arabidopsis thaliana (L.). Plant Sci 164:195-202

Feng Z, Guo A, Feng Z (2003) Amelioration of chilling stress by triadimefon in cucumber seedlings. Plant Growth Regul 39:277-283

Foyer CH, Noctor G (2005) Oxidant and antioxidant signalling in plants: a reevaluation of the concept of oxidative stress in a physiological context. Plant Cell Environ 28:1056-1071

Ghazi-Khansaria M, Mojarrab M, Ahmadi F, Hosseinzadeh L (2013) The antiproliferative effects of petroleum ether extract of Artemisia aucheri on human cancerous cell lines. J Rep Pharm Sci 2(2):61-66

Gill SS, Tuteja N (2010) Reactive oxygen species and antioxidant machinery in abiotic stress tolerance in crop plants. Plant Physiol Biochem 48:909-930. doi:10.1016/j.plaphy.2010.08.016

Girma FS, Krieg DR (1992) Osmotic adjustment in sorghum I. Mechanisms of diurnal osmotic potential changes. Plant Physiol 99:577-582

Habibi G (2012) Exogenous salicylic acid alleviates oxidative damage of barley plants under drought stress. Acta Biol Szeged 56(1):57-63

Hajihashemi S, Geuns JM, Ehsanpour AA (2013) Gene transcription of steviol glycoside biosynthesis in Stevia rebaudiana Bertoni under polyethylene glycol, paclobutrazol and gibberellic acid treatments in vitro. Acta Physiol Plant 35:2009-2011

Harfouche AL, Rugini E, Mencarelli F, Botondi R, Muleo R (2008) Salicylic acid induces $\mathrm{H}_{2} \mathrm{O}_{2}$ production and endochitinase gene expression but not ethylene biosynthesis in Castanea sativa in vitro model system. J Plant Physiol 165:734-744

Hashemi P, Abolghasemi M, Fakhari A, Ebrahimi SN, Ahmadi S (2007) Hydrodistillation-solvent microextraction and GC-MS identification of volatile components of Artemisia aucheri. Chromatographia 66:283-286

He Q, Zhao S, Ma Q, Zhang Y, Huang L, Li G, Hao L (2014) Endogenous salicylic acid levels and signaling positively regulate Arabidopsis response to polyethylene glycol-simulated drought stress. J Plant Growth Regul 33:871-880

Heath RL, Packer L (1968) Photoperoxidation in isolated chloroplasts: I. Kinetics and stoichiometry of fatty acid peroxidation. Arch Biochem Biophys 125:189-198

Horváth E, Janda T, Szalai G, Páldi E (2002) In vitro salicylic acid inhibition of catalase activity in maize: differences between the isozymes and a possible role in the induction of chilling tolerance. Plant Sci 163:1129-1135

Horváth E, Szalai G, Janda T (2007) Induction of abiotic stress tolerance by salicylic acid signaling. J Plant Growth Regul 26:290-300

Hosseini S, Kappas M, Chahouki MZ, Gerold G, Erasmi S, Emam AR (2013) Modelling potential habitats for Artemisia sieberi and Artemisia aucheri in Poshtkouh area, central Iran using the maximum entropy model and geostatistics. Ecol Inform 18:61-68

Kadioglu A, Saruhan N, Sağlam A, Terzi R, Acet T (2011) Exogenous salicylic acid alleviates effects of long term drought stress and delays leaf rolling by inducing antioxidant system. Plant Growth Regul 64:27-37

Kang G, Li G, Guo T (2014) Molecular mechanism of salicylic acid-induced abiotic stress tolerance in higher plants. Acta Physiol Plant 36:2287-2297

Khokon M et al (2011) Involvement of extracellular oxidative burst in salicylic acid-induced stomatal closure in Arabidopsis. Plant Cell Environ 34:434-443
Law M, Charles SA, Halliwell B (1983) Glutathione and ascorbic acid in spinach (Spinacia oleracea) chloroplasts. The effect of hydrogen peroxide and of paraquat. Biochem J 210:899-903

Li D-M, Zhang J, Sun W-J, Li Q, Dai A-H, Bai J-G (2011) 5-Aminolevulinic acid pretreatment mitigates drought stress of cucumber leaves through altering antioxidant enzyme activity. Sci Hortic 130:820-828

Luo Y, Su Z, Bi T, Cui X, Lan Q (2014) Salicylic acid improves chilling tolerance by affecting antioxidant enzymes and osmoregulators in sacha inchi (Plukenetia volubilis). Braz J Bot 37:357-363

Lutts S, Kinet J, Bouharmont J (1995) Changes in plant response to $\mathrm{NaCl}$ during development of rice (Oryza sativa L.) varieties differing in salinity resistance. J Exp Bot 46:1843-1852

Mittler R (2002) Oxidative stress, antioxidants and stress tolerance. Trends Plant Sci 7:405-410

Miura K, Tada Y (2014) Regulation of water, salinity, and cold stress responses by salicylic acid. Front Plant Sci 5:4. doi:10.3389/fpls.2014.00004

Molassiotis A, Sotiropoulos T, Tanou G, Diamantidis G, Therios I (2006) Boroninduced oxidative damage and antioxidant and nucleolytic responses in shoot tips culture of the apple rootstock EM 9 (Malus domestica Borkh). Environ Exp Bot 56:54-62

Mozaffarian V (2010) Flora of Iran (composite). Iranian Research Institute of Forest and Rangeland Press, Tehran

Murashige T, Skoog F (1962) A revised medium for rapid growth and bio assays with tobacco tissue cultures. Physiol Plant 15:473-497

Nakano Y, Asada K (1986) Purification of ascorbate peroxidase in spinach chloroplasts; its inactivation in ascorbate-depleted medium and reactivation by monodehydroascorbate radical. Plant Cell Physiol 28(1):131-140

Nazar R, lqbal N, Syeed S, Khan NA (2011) Salicylic acid alleviates decreases in photosynthesis under salt stress by enhancing nitrogen and sulfur assimilation and antioxidant metabolism differentially in two mungbean cultivars. J Plant Physiol 168:807-815. doi:10.1016/j.jplph.2010.11.001

Nazar R, Umar S, Khan N, Sareer O (2015) Salicylic acid supplementation improves photosynthesis and growth in mustard through changes in proline accumulation and ethylene formation under drought stress. S Afr J Bot 98:84-94

Noctor G, Foyer CH (1998) Ascorbate and glutathione: keeping active oxygen under control. Annu Rev Plant Biol 49:249-279

Plewa MJ, Smith SR, Wagner ED (1991) Diethyldithiocarbamate suppresses the plant activation of aromatic amines into mutagens by inhibiting tobacco cell peroxidase. Mutat Res Fundam Mol Mech Mutagen 247:57-64

Podlech D (1986) Artemisia L. In: Rechinger KH (ed) Flora Iranica, vol 158. Akademische Druck- und Verlagsanstalt, Graz, pp 159-223

Pyngrope S, Bhoomika K, Dubey RS (2013) Reactive oxygen species, ascorbate-glutathione pool, and enzymes of their metabolism in droughtsensitive and tolerant indica rice (Oryza sativa L.) seedlings subjected to progressing levels of water deficit. Protoplasma 250:585-600. doi:10.1007/s00709-012-0444-0

Rady MM, Mohamed GF (2015) Modulation of salt stress effects on the growth, physio-chemical attributes and yields of Phaseolus vulgaris L. plants by the combined application of salicylic acid and Moringa oleifera leaf extract. Sci Hortic 193:105-113

Ramakrishna A, Ravishankar GA (2011) Influence of abiotic stress signals on secondary metabolites in plants. Plant Signal Behav 6:1720-1731

Rivas-San Vicente M, Plasencia J (2011) Salicylic acid beyond defence: its role in plant growth and development. J Exp Bot 62:3321-3338

Rustaiyan A, Bamonieri A, Raffatrad M, Jakupovic J, Bohlmann F (1987) Eudesmane derivatives and highly oxygenated monoterpenes from Iranian Artemisia species. Phytochemistry 26:2307-2310

Saruhan N, Saglam A, Kadioglu A (2012) Salicylic acid pretreatment induces drought tolerance and delays leaf rolling by inducing antioxidant systems in maize genotypes. Acta Physiol Plant 34:97-106

Sekmen AH, Ozgur R, Uzilday B, Turkan I (2014) Reactive oxygen species scavenging capacities of cotton (Gossypium hirsutum) cultivars under combined drought and heat induced oxidative stress. Environ Exp Bot 99:141-149

Shakirova FM, Allagulova CR, Maslennikova DR, Klyuchnikova EO, Avalbaev AM, Bezrukova MV (2016) Salicylic acid-induced protection against cadmium toxicity in wheat plants. Environ Exp Bot 122:19-28. doi:10.1016/j. envexpbot.2015.08.002 
Sharif M, Ziaei H, Azadbakht M, Daryani A, Ebadattalab A, Rostami M (2006) Effect of methanolic extracts of Artemisia aucheri and Camellia sinensis on Leishmania major (in vitro). Turk J Med Sci 36(6):365-369

Shen C, Hu Y, Du X, Li T, Tang H, Wu J (2014) Salicylic acid induces physiological and biochemical changes in Torreya grandis cv. Merrillii seedlings under drought stress. Trees 28:961-970

Smith IK, Vierheller TL, Thorne CA (1988) Assay of glutathione reductase in crude tissue homogenates using 5,5'-dithiobis(2-nitrobenzoic acid). Anal Biochem 175:408-413

Suzuki N, Koussevitzky S, Mittler R, Miller G (2012) ROS and redox signalling in the response of plants to abiotic stress. Plant Cell Environ 35:259-270

Szalai G, Kellős T, Galiba G, Kocsy G (2009) Glutathione as an antioxidant and regulatory molecule in plants under abiotic stress conditions. J Plant Growth Regul 28:66-80. doi:10.1007/s00344-008-9075-2
Velikova V, Yordanov I, Edreva A (2000) Oxidative stress and some antioxidant systems in acid rain-treated bean plants: protective role of exogenous polyamines. Plant Sci 151:59-66

Wang W-B, Kim Y-H, Lee H-S, Kim K-Y, Deng X-P, Kwak S-S (2009) Analysis of antioxidant enzyme activity during germination of alfalfa under salt and drought stresses. Plant Physiol Biochem 47:570-577

Willekens $\mathrm{H}$ et al (1997) Catalase is a sink for $\mathrm{H}_{2} \mathrm{O}_{2}$ and is indispensable for stress defence in C3 plants. EMBO J 16:4806-4816

Ying Y et al (2013) Salicylic acid induces physiological and biochemical changes in three Red bayberry (Myric rubra) genotypes under water stress. Plant Growth Regul 71:181-189

\section{Submit your manuscript to a SpringerOpen ${ }^{\circ}$ journal and benefit from:}

- Convenient online submission

- Rigorous peer review

- Immediate publication on acceptance

- Open access: articles freely available online

- High visibility within the field

- Retaining the copyright to your article 